\title{
Amazônia, uma história de impactos e exposição ambiental em paralelo à instalação de grandes empreendimentos na região
}

Amazon, a history of impacts and environmental exposure in parallel with the installation of large projects in the region

Amazonía, una historia de impactos y exposición ambiental en paralelo a la instalación de grandes emprendimientos en la región

A Amazônia é amplamente conhecida por suas exuberantes florestas e suas funções climáticas, grande disponibilidade de águas doces e presença em seu subsolo de riquezas minerais, tudo isso associado a belezas naturais únicas em todo o planeta. Porém, nas últimas décadas, a região vem passando por grandes transformações que resultaram, entre outras coisas, em crescimento demográfico, a população passou de 4,7 para 13 milhões no período de 1980 a 2000', com significativo aumento no despejo no ambiente de resíduos sólidos urbanos (RSU) e efluentes domésticos e sanitários não tratados, como vem ocorrendo no lixão a céu aberto, próximo ao rio Aurá, o qual foi o destino por quase 30 anos de todo RSU oriundo da Região Metropolitana de Belém, Estado do Pará2,3.

A região tem sido cenário de acontecimentos que produzem consequências complexas para o equilíbrio do ambiente e das sociedades humanas na região, dentre os quais se destacam: 1) o aumento da exploração ilegal de madeira, desmatamento de áreas de floresta, terras e florestas destinadas à agropecuária e maior uso de agrotóxicos, como vem ocorrendo nas margens da BR-163 e também no Estado de Roraima, alimentando e agravando também os conflitos históricos entre índios, ribeirinhos e produtores de grãos ${ }^{4}$; 2 ) a instalação de hidrelétricas e formação de lagos imensos que modificam profundamente o equilíbrio dos ecossistemas aquáticos e alteram hábitos das populações tradicionais, como ocorrido na década de 80, em Tucurui, Estado do Pará, ou mais recentemente durante as construções das hidrelétricas de Belo Monte, no mesmo Estado, e em Santo Antônio e Jirau, no Estado de Rondônia ${ }^{5}$; 3) implantação e ampliação da atividade industrial e mineral, com fortes incrementos na polvição do ar e produção de resíduos e efluentes que chegam aos corpos hídricos, modificando suas características naturais, ou são armazenados em grandes bacias de deposição, cujos deficientes controles de órgãos de saúde e ambientais mostram um histórico de danos ambientais e riscos à saúde humana, após sequenciais etapas de transbordamentos ou rompimentos ${ }^{6}$.

Devemos ressaltar que o histórico de danos ambientais e exposição humana a polventes relacionados a estas atividades industriais e minerais são graves e relevantes, enfatizando: 1) os ocorridos desde 2001 em Barcarena (Figura 1), Estado do Pará; 2) o passivo deixado, desde a década de 1970, no fundo do Lago do Batata, em Oriximiná, Estado do Pará; 3) os danos ambientais e conflitos sociais ocorridos em Serra do Navio e Santana, Estado do Amapá, durante e após o encerramento das atividades de exploração de extração e beneficiamento de minério manganês por mais de 50 anos; 4) o histórico lançamento de mercúrio devido à mineração artesanal de ouro, principalmente no Vale do Rio Tapajós, desde a década de 19707,8,9.

O drástico de tudo isso é que, além dos problemas elencados, a instalação de grandes empreendimentos na Amazônia não significou grandes melhorias de infraestrutura ou nos serviços públicos de transporte, saúde e educação para a população dos municípios que, direta ou indiretamente, foram afetados com os impactos ambientais e danos aos ecossistemas aquáticos e saúde humana ${ }^{10}$. Nestes casos, os escassos empregos disponíveis para a população local são, na sua maioria, em atividades associadas à prestação de serviços com baixa remuneração e caracterizada, muitas vezes, pela precariedade do trabalho ou até mesmo nas relações de trabalho. Apesar destes serem empregos dignos, devemos ressaltar que a maior parte dos cargos técnicos disponíveis - e de melhor remuneração - exigem níveis de qualificação que não são acessíveis nestas cidades e acabam sendo destinados a profissionais que migram de outras regiões do Brasil e até mesmo de outros países ${ }^{11}$. Esta é uma realidade também de fácil constatação nos diversos empreendimentos industriais, minerais e hidrelétricos espalhados por toda a Amazônia. 

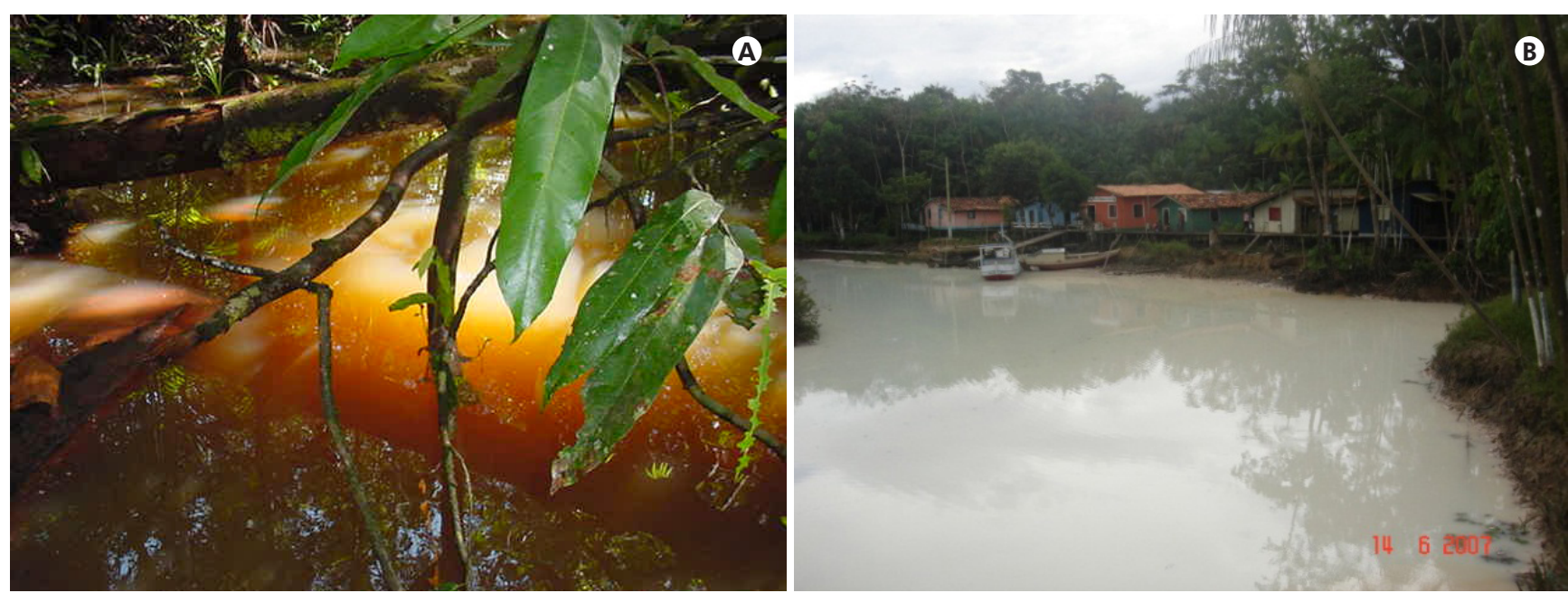

Figura 1 - Vazamento de lama vermelha (A) e efluentes do processo de beneficiamento de caulim (B) em Barcarena, Estado do Pará, Brasil

Também é certo que a capacidade técnica e tecnológica instalada na região ainda é bastante limitada e emitir licenças ambientais ou, até mesmo, monitorar e fiscalizar as atividades em andamento tornaram-se tarefas complexas e com falhas em quase todas as etapas, situação que se agrava pelas dimensões continentais e que exigem logísticas de campo custosas e demoradas ${ }^{12}$. Este é um aspecto de grande obscuridade, pois aponta também para a deficiência do poder público na obtenção de dados mais precisos e acaba deixando boa parte de nossa população à mercê da exposição ambiental a contaminantes a partir de rotas pouco conhecidas e que demoram a ser detectadas apenas pela disponibilidade de informações dos próprios empreendimentos ${ }^{6}$.

Estas observações nos trazem reflexões e grandes preocupações, tanto para a preservação ambiental da Amazônia quanto sobre os impactos na qualidade de vida de toda população que nela reside. Precisamos reavaliar os modelos de licenciamento de impactos ambientais que não consideram o desenvolvimento humano como um aspecto importante e necessário, e omitem os reais impactos ambientais e riscos à saúde de grandes empreendimentos num planejamento de gradativo aumento de produtividade. Porém, também devemos estimular um amplo debate na sociedade sobre qual modelo de desenvolvimento desejamos.

\section{REFERÊNCIAS}

1 Instituto Brasileiro de Geografia e Estatística. Censo demográfico da região: Pesquisa Nacional de Saneamento Básico. Rio de Janeiro: IBGE; 2010.

2 Fearnside PM. A floresta amazônica nas mudanças globais. Manaus: Instituto Nacional de Pesquisas da Amazônia; 2003.

3 Ferreira LV, Venticinque E, Almeida S. O desmatamento na Amazônia e a importância das áreas protegidas. Est Av. 2005 jan-abr; 19(53):157-66.

4 Vieira ICG, Silva JMC, Toledo PM. Estratégias para evitar a perda de biodiversidade na Amazônia. Est Av. 2005 mai-ago; 19(54): 153-64.

5 Manyari WV. Impactos ambientais a jusante de hidrelétricas, o caso da usina de Tucuruí, PA [tese]. Rio de Janeiro: Universidade Federal do Rio de Janeiro; 2007.

6 Licco EA. Avaliação de risco como ferramenta complementar ao licenciamento de fontes de polvição envolvendo polventes tóxicos do ar. Interfacehs. 2008 jan-abr;3(1):1-19.

7 Instituto Evandro Chagas. Relatório técnico SAMAM 001: caracterização dos impactos ambientais, danos ao ecossistema e riscos à saúde decorrentes do lançamento no rio Murucupi de efluentes do processo de beneficiamento de bauxita, Barcarena, Pará. Ananindeua: IEC; 2009.

8 Lima MO, Santos ECO, Jesus IM, Medeiros AC, Faial KCF, Alves CN. Assessment of surface water in two Amazonian rivers impacted by industrial wastewater, Barcarena city, Pará State (Brazil). J Braz Chemical Soc. 2011 Aug;22(8):1-12. 
9 Bozelli RL, Esteves FA, Roland F, editores. Lago do batata: impacto e recuperação de uma ecossistema amazônico. Rio de Janeiro: Sociedade Brasileira de Limnologia, UFRJ ; 2001.

10 Costa BNS, Pinheiro SCC, Amado LL, Lima MO. Microzooplankton as a bioindicator of environmental degradation in the Amazon. Ecol Indic. 2016 Feb;61 Part 2;526-45.

11 Dupas G. A lógica da economia global e a exclusão social. Est Av. 1998 set-dez; 12(34):121-59.

12 Fatorelli L, Mertens F. Integração de políticas e governança ambiental: o caso do licenciamento rural no Brasil. Ambient Soc. 2010 dez;13(2):401-15.

Marcelo de Oliveira Lima Editor Científico da Revista Pan-Amazônica de Saúde Pesquisador em Saúde Pública do Instituto Evandro Chagas/SVS/MS, Ananindeua, Pará, Brasil 